\title{
Dühr, Stefanie; Colomb, Claire; Nadin, Vincent (2010): European Spatial Planning and Territorial Cooperation
}

\author{
London: Routledge. 32 Tab., 24 Abb., 10 Farbabb., 36 Box., 452 S.
}

\author{
Bas Waterhout
}

Received: 1 September 2010 / Accepted: 15 November 2010 / Published online: 11 December 2010

C The Author(s) 2010. This article is published with open access at Springerlink.com

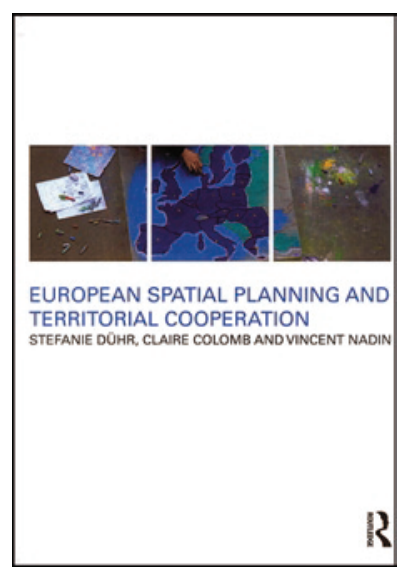

As all teachers of European spatial planning know, providing a balanced and comprehensive list of literature to students is a challenge. This was also the experience of the authors of "European Spatial Planning and Territorial Cooperation", who all have been involved in research, practice and higher education in the field of European spatial planning for many years. So, this book has, at least partly, arisen out of the authors" "own needs for an up-to-date, critical textbook (...) informed by the latest available research" (p. xix). Another driving force is the firmly stated belief that "inadequately guided (...) spatial development (...) is a recipe for environmental damage and regressive social and economic impacts" (p. xx). The authors believe, that despite the uncertainties surrounding spatial planning, "it is an absolute primary requirement of government. (...) And Europeans need to do it together" (p. xx). In other words, this book is written with a purpose and aims to fill a void.

Dr. B. Waterhout $(\bowtie)$

OTB Research Institute for the Built Environment, Delft University of Technology, P.O. Box 5030,

2600 GA Delft, Netherlands

e-mail: b.waterhout@tudelft.nl
The last comprehensive textbook on the subject was "European Union spatial policy and planning" by the late Dick Williams. However, that pioneering textbook was written in 1996 when the field was easy to oversee and the 'European spatial planning community' comprised of a hundred or so persons who all knew each other. Now, the situation is far more complex and the field, which is increasingly difficult to demarcate, like the European Union itself, has expanded considerably. The number of involved parties and stakeholders easily goes into thousands.

So what is in the book? First of all, the book is about spatial planning for Europe, which is something different than spatial planning in Europe (i.e. in member states and regions). It is about the attempts and achievements to coordinate spatial development at a transnational and EU wide scale (and even beyond) and to cooperate on territorial issues across national borders.

The book comes in six parts, each part consisting of three to six chapters, amounting to 25 chapters in total. Each chapter starts with a relevant quote. The first part introduces the 'European dimension of spatial planning' by means of discussing the EU as a planning subject, arguing for and against European spatial planning and alluding to language and terminology issues. Part 2 discusses spatial development trends in Europe, how to understand and represent them, paying attention to the seminal issue of maps, and what data and information sources are available anyhow to monitor these developments. Part 3 explains in six chapters the working of the European Union as a political system, considers possible theoretical approaches to EU governance and policy-making, debates its institutions and other relevant stakeholders, the decision making procedures and the widening and deepening of the EU. Part 4 introduces the efforts of spatial planners to develop European spatial planning agendas and policies. It discusses the history of these attempts, which goes back to 
the 1950s, and refers to major players (i.e. influential member states) and landmarks such as the European Spatial Development Perspective (ESDP), the establishment of INTERREG and the European Spatial Planning Observation Network (ESPON) as well as other achievements. Part 5 discusses the territorial effects of EU sector policies in the fields of agriculture and rural development, economy and competition, transport, cohesion, urban development and environment. Part 6, finally, discusses how European spatial planning can result in new forms of territorial governance across boundaries as well as within member states and regions, as a result of processes of Europeanisation and convergence or divergence between planning cultures. The book closes with a chapter in which the authors look back and forward.

What makes this book useful is that it manages to present in a clear, neutral and accessible style indeed a comprehensive picture of European spatial planning. All aspects (and I really mean all) and nearly all references, including some pretty obscure ones, relevant for the subject are addressed, even the new ones, like the EU strategy for the Baltic Sea, or the Barca Report. The book carefully explains each aspect of European spatial planning, its background, why it is relevant and how it is interrelated to other aspects. In doing so it does not confine itself to the 'narrow' topic of European spatial planning as such, but provides information, too, on relevant contextual issues and questions, like, for example, 'where does Europe stop?' (p. 169), or several theoretical perspectives on European integration as such.

Of course, it is possible to criticize individual chapters or passages, but most of such comments would be nitpicking. The book does not always provide definitive answers for each and every subject. It explains various perspectives and interpretations on a specific topic or area, leaving the definitive answer up to the reader.

Being a textbook, the publication is limited by the availability of (academic) literature. The area of interest where this shows most concerns is the spatial impact of EU sectoral policies - part 5 of the book. The impact of EU policies is one of the politically most contested and debated issues. In particular local development projects are often being influenced by habitat, air quality or procurement directives. Whereas this may be reflected in local newspaper articles, it has not resulted in many academic publications to date. Providing a detailed picture of impact across Europe therefore is a daunting task, the more so because impact of EU sector policies differs from member state to member state. Chapters 17 to 21 therefore present in more general terms the development and objectives of specific EU sector policies and their territorial influence at, mainly, a European scale. Next to the more obvious choices, like transport and agriculture, it should be applauded that the authors opted for a chapter on the impact of economic and competition policy, a policy field which has considerable spatial impact, but is not well understood. Chapter 23 on the Europeanisation of planning in member states sheds some light on the combined impact of EU policies on territorial development. Obviously, whereas these chapters form a more than adequate start, there is much scope in this field for further analyses and research (an issue that the authors raise on pp. 393394); in particular as regards the impact on territorial governance (i.e. how spatial planning decision making processes are being influenced).

If anything, what is missing in the book is a sense of how European spatial planning agendas have come about. The agendas and programmes are presented as if they simply have always been there. In reality, however, the formation processes of the ESDP, INTERREG or ESPON, to name some proud achievements of European spatial planners (a label for a very heterogeneous bunch of policy makers), but also of including territorial cohesion issues in some paragraphs in the Commission's Cohesion Reports or article 3 of the Lisbon Treaty, have been the result of individuals or just a few people fighting and lobbying hard and persistently, with often luck or coincidence having been the decisive factor for success. There is little attention to the committees and working groups, some of which have a long history and represent fora where much of the negotiation and lobbying is taking place behind the screens. The book does not really show how key players' attitudes towards planning and territorial cohesion have changed over time, like for example the ever more important European Parliament.

Would I recommend the book? Almost without hesitation. In my opinion this is not a book for first year undergraduate students. In order to understand the European spatial planning and appreciate the richness of the book, one needs at least to have basic knowledge of a spatial planning system and policy in Europe. But with that out of the way, this incredibly complete, encyclopedia-like opus is nothing less than a superb achievement that should become the standard reference for students, lecturers, practitioners and researchers in the field of European spatial planning. It is hopefully to become the first in a series of regularly updated editions.

The book ends as it starts, with a strong message. And although, according to the authors, "it is impossible to end this book with firm conclusions" (p. 394), they point out, that the neoliberal turn in governance is undermining the 'European social model', which makes the future of European spatial planning less than certain (pp. 390-394). While I share their concerns, my personal opinion is a more positive one, in sense that the attention for the territorial dimension of European policies has become stronger. I am sure that this very book will play an important role in this process itself.

Open Access This article is distributed under the terms of the Creative Commons Attribution Noncommercial License which permits any noncommercial use, distribution, and reproduction in any medium, provided the original author(s) and source are credited. 